\title{
Evaluation of Patients with Dengue Infection for Their Clinical and Hematological Profile, Management and Outcomes at Mount Zion Medical College Hospital in Kerala
}

\author{
Ajit Kovil $^{1}$ \\ ${ }^{1}$ Mount Zion Medical College Hospital, Ezhamkulam, Adoor Pathanamthitta Dist, Kerala.
}

\section{Abstract}

Background: Dengue Fever which is also known as break bone fever is a benign syndrome begin by many arthropod- borne viruses, which is specify by myalgia, high grade fever, or arthralgia, rash, leukopenia and lymphadenopathy. Our study was carried out with an aim to describe the different clinical spectrums of dengue with its hematological profile. Subjects and Methods: A total of 130 cases were anticipated with age of all groups, and those who were serologically positive for Dengue tested by ELISA/Card (NS1, IgG, IgM) method were included in this study. Patients found to be serologically dengue negative and positive patients who were also found to be positive for $\square$ other coexisting infections, viz. malaria, typhoid, etc and not done the clinical test were excluded, so this study included all patients diagnosed with dengue. The examination based on WHO criteria and the case definition was based on compatible clinical history and, confirmed by positive serology for dengue applying the ELISA IgM method. All patients with bleeding manifestations, thrombocytopenia with platelet count $<30,000 \mathrm{cu} / \mathrm{mm}$ were admitted and pregnant patients and infants with decrees platelet counts were admitted. Results: Out of a total of 130 cases enrolled in the study a total of $75(58 \%)$ did not have bleeding manifestations and comprised the Group I of study where as remaining 55(42\%)patients presented with bleeding manifestations and were placed in Group II of study. Among these 130 patients with confirmed diagnosis, 75 were Group I while the rest were Group II giving a Group I to Group II. Their ages ranged from 4 years to 80 years. Conclusion: In the current study the clinical profile of patients having bleeding manifestations which is the extreme form of dengue fever was marked by raised portion of hepatomegaly and decreased platelet count. The clinical course of disease is marked by a rationalization of platelet count by day 5 of illness. Dengue fever does not have specific medical therapy hence clinical recovery monitoring is largely dependent on haematological parameters. This study concludes that parameter like platelet count, haematocrit, leukocyte count and coagulation studies aid greatly in clinical monitoring of patient.

Keywords: Dengue, hematological profile, management, outcomes.

Corresponding Author: Dr. Ajit Kovil, Mount Zion Medical College hospital, Ezhamkulam, Adoor Pathanamthitta Dist, Kerala.

Received: 04 January 2017

Accepted: 17 January 2017

\section{Introduction}

Dengue Fever which is also known as break bone fever is a benign syndrome begin by many arthropod- borne viruses, which is specify by myalgia, high grade fever, or arthralgia, rash, leukopenia and lymphadenopathy. the disease develops in to the life-threatening dengue hemorrhagic fever In a small proportion of cases, with the consequences of bleeding, blood platelets decrees levels and leakage of blood plasma, or grievously decrees blood pressure occurs this condition is called dengue shock syndrome. ${ }^{[1]}$ In urban areas dengue fever with alarming signals and severe dengue with critical leakage of plasma, severe bleeding or acute organ intimacy have emerged as influential public health threat. This is referable to migration of population to cities emerging in urban over peopled and infrastructure construction in these areas providing unhindered appropriation for Propagation of the vector. ${ }^{[2]}$ A period of time especially the months of May to September there is a seasonal growth in the number of cases presenting to the emergency and outpatient departments which imposes an additional load to an already overburdened system particularly for staffing, laboratory and acute ward entry. The clinical symptoms of Dengue Fever is triphasic with the febrile phase particularly specify by high grade fever, headache, myalgia, body ache, vomiting, joint pain, transient rash and mild bleeding manifestations such as petichiae, ecchymosis at pressure sites and bleeding from venipunctures. ${ }^{[3]}$ there is a major probability of advancement of the patient to critical dengue which is characterized by existence of plasma leakage which may lead to shock or accumulation of fluid such as ascites or pleural effusion with or without respiratory distress, severe bleeding, and severe organ impairment in the next critical phase. ${ }^{[4]}$ The incidence of dengue infection has expanded In recent decades throughout the world and has become a big international public health trouble. DF is endemic in India, especially in the northern regions and now endemic in more than 100 
tropical and sub-tropical countries. Our study was carried out with an aim to describe the different clinical spectrums of dengue with its hematological profile. Few patients suffering from DF evolve the more severe form of the disease DHF with symptoms that comprise a decline in fever and presentation of hemorrhagic manifestations, such as microscopic hematuria, bleeding gums, epistaxis, hematemesis, melina, and ecchymosis. If not treated, these patients may progress into DSS, which can lead to profound shock and death. Advance clinical symptoms of DSS have accute abdominal pain, protracted vomiting, and a notable change in temperature from fever to hypothermia. ${ }^{[5]}$

\section{Clinical Diagnostic criteria of DHF (WHO) ${ }^{[4]}$}

1. Sustained high fever lasting 2-7 days;

2. Petechiae or epistaxis with a positive tourniquet test

3. Thrombocytopenia (platelet count $=100 \times 109 / \mathrm{L}$ ); and

4. Evidence of plasma leakage - hemoconcentration (an increase in hematocrit $=20 \%$ above average for age, sex and population), pleural effusion and ascites. ${ }^{[4]}$

Hence, the diagnosis of dengue fever is carried out based on clinical, epidemiological and laboratory data. In this context, the present study aimed to assess the hematological profile of patients with dengue fever.

\section{Subjects and Methods}

A one year retrospective study was conducted in Department of Medicine, at mount zion Medical College hospital, Ezhamkulam, Adoor Pathanamthitta Dist, Kerala. A total of 130 cases were anticipated with age of all groups, and those who were serologically positive for Dengue tested by ELISA/Card (NS1, IgG, IgM) method were included in this study. Patients found to be serologically dengue negative and positive patients who were also found to be positive for $\square$ other coexisting infections, viz. malaria, typhoid, etc and not done the clinical test were excluded, so this study included all patients diagnosed with dengue. The examination based on WHO criteria and the case definition was based on compatible clinical history and, confirmed by positive serology for dengue applying the ELISA $\operatorname{IgM}$ method. All patients with bleeding manifestations, thrombocytopenia with platelet count $<30,000 \mathrm{cu} / \mathrm{mm}$ were admitted and pregnant patients and infants with decrees platelet counts were admitted. The mainstay of therapy was maintenance of hydration status and early recognition of plasma leakage and shock. Management of cases was done strictly as per the guidelines for clinical management of dengue. ${ }^{[4]}$ Paracetamol was prescribed to patients for fever and pain relief with full voidance of any other non steroidal analgesic (NSAID). Patients were treated with oral rehydration therapy, intravenous (IV) fluid therapy, packed red blood cell (PRBC) transfusion, platelet concentrates depending upon the clinical condition. Patients with DF were managed with oral rehydration salt (ORS) solution, oral paracetamol and advised review every 3 days. The following hematological parameters were noted: Haemoglobin $(\mathrm{Hb})$, Total leukocyte count (TLC), Hematocrit (Hct), Platelet count (PC), Prothrombin time (PT), Activated Partial Thromboplastin Time (APTT). Following biochemical parameters were also assessed: Aspartate aminotransferase (AST), Alanine aminotransferase (ALT), Albumin, Alkaline phosphatase (ALP). All the patients were followed uptillday. ${ }^{[5]}$ Are peat blood sample was taken at day 3 and day 5 after admission for platelet count evaluation.

\section{Results}

Out of a total of 130 cases enrolled in the study a total of 75 $(58 \%)$ did not have bleeding manifestations and comprised the Group I of study where as remaining 55(42\%) patients presented with bleeding manifestations and were placed in Group II ofstudy. Among these 130 patients with confirmed diagnosis, 75Were Group I while the rest were Group II giving a Group I to Group II. Their ages ranged from 4 years to 80 years. [Table 1, Figure 1]

Table 1: Age distribution of patients with dengue fever $(n=$ 130).

\begin{tabular}{|l|l|l|}
\hline SN & Age Group & Total $(\mathbf{n = 1 3 0})$ \\
\hline 1 & $\leq 10$ Years & 14 \\
\hline 2 & $11-20$ Years & 28 \\
\hline 3 & $21-30$ Years & 24 \\
\hline 4 & 31-40 Years & 23 \\
\hline 5 & 41-50 Years & 17 \\
\hline 6 & 51-60 Years & 15 \\
\hline 7 & 61-70 Years & 4 \\
\hline 8 & $71-80$ Years & 5 \\
\hline Total & 130 \\
\hline
\end{tabular}

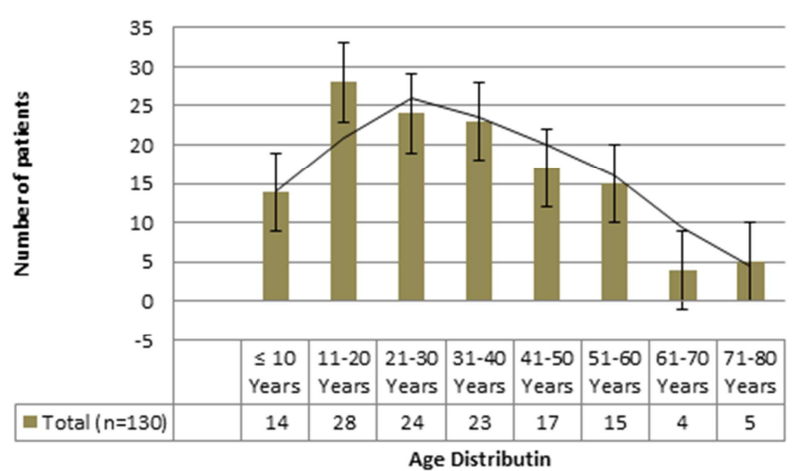

Figure 1: Age distribution of patients with dengue fever $(n=$ 130)

\begin{tabular}{|c|c|c|c|c|c|c|}
\hline \multirow[t]{2}{*}{ SN } & \multirow[t]{2}{*}{ Age Group } & \multirow[t]{2}{*}{$\begin{array}{l}\text { Total } \\
(n=130)\end{array}$} & \multicolumn{2}{|c|}{$\begin{array}{l}\text { Group } \\
(n=75)\end{array}$} & \multicolumn{2}{|c|}{$\begin{array}{l}\text { Group } \\
(n=55)\end{array}$} \\
\hline & & & No. & $\%$ & No. & $\%$ \\
\hline 1 & $\leq 10$ Years & 14 & 10 & 13.3 & 4 & 7.2 \\
\hline 2 & 11-20 Years & 28 & 14 & 18.6 & 14 & 25.4 \\
\hline 3 & 21-30 Years & 24 & 16 & 21.3 & 8 & 14.5 \\
\hline 4 & 31-40 Years & 23 & 12 & 16 & 11 & 20 \\
\hline 5 & $41-50$ Years & 17 & 11 & 14.6 & 6 & 10.9 \\
\hline 6 & $51-60$ Years & 15 & 8 & 10.6 & 7 & 12.7 \\
\hline 7 & $61-70$ Years & 4 & 2 & 2.6 & 2 & 3.6 \\
\hline 8 & $71-80$ Years & 5 & 3 & 4 & 2 & 3.6 \\
\hline \multicolumn{2}{|c|}{$\begin{array}{l}\text { Mean Age } \pm \text { SD } \\
\text { (Range) in Years }\end{array}$} & $\begin{array}{l}35.12 \pm 18.64 \\
(4-80)\end{array}$ & \multicolumn{2}{|c|}{$\begin{array}{l}34.93 \pm 18.18 \\
(6-75)\end{array}$} & \multicolumn{2}{|c|}{$\begin{array}{l}15.37 \pm 19.49 \\
(4-80)\end{array}$} \\
\hline
\end{tabular}

Age of patients ranged from 4 to 80 years. The distribution of cases is described below, on comparing in two groups statistically, the difference was not found to be significant 
$(\mathrm{p}=0.917)$. [Table 2]

Clinically, fever was the most common complaint seen in all the patients. Body ache was the next most common complaint $(66 \%)$ followed by vomiting $(50 \%)$, bleeding $(55 \%)$, hepatomegaly $(44 \%)$,rashes $(38 \%)$ and petechie by tourniquet test (32\%) respectively. On comparing the two groups, statistically, no significant difference was observed with respect to presence of fever, rashes, body ache, vomiting and tourniquet. However, incidence of hepatomegaly and bleeding was significantly higher in Group II as compared to that in Group I $(p<0.001)$. In fact, all the 45 cases with bleeding manifestation were in Group II as it was the criteria for differentiation between two groups. [Table 3]. Hematological profile of cases were shown in [Table 4].

\begin{tabular}{|c|c|c|c|c|c|c|c|c|}
\hline \multirow{3}{*}{ SN } & le 3: Distri & on of ca & es A & ard & & ini & $\mathrm{Pr}$ & itatiol \\
\hline & \multirow[t]{2}{*}{ Finding } & \multirow[t]{2}{*}{$\begin{array}{l}\text { Total } \\
(\mathrm{n}=130\end{array}$} & \multicolumn{2}{|c|}{$\begin{array}{l}\text { Group I } \\
(\mathrm{n}=75)\end{array}$} & \multicolumn{2}{|c|}{$\begin{array}{l}\text { Group II } \\
(\mathrm{n}=55)\end{array}$} & \multicolumn{2}{|c|}{$\begin{array}{l}\text { Statistical } \\
\text { significance }\end{array}$} \\
\hline & & & No. & $\%$ & No. & $\%$ & $\square 2$ & 'p' \\
\hline 1 & Fever & 130 & 75 & 100 & 55 & 100 & - & \\
\hline 2 & Rashes & 38 & 22 & 29.3 & 16 & 29.1 & 0.275 & 0.619 \\
\hline 3. & Hepatomegaly & 44 & 16 & 21.3 & 28 & 50.9 & 11.78 & 0.001 \\
\hline 4. & Bodyache & 66 & 35 & 46.6 & 31 & 56.3 & 0.276 & 0.629 \\
\hline 5. & Vomiting & 50 & 27 & 36 & 23 & 41.8 & 0.029 & 0.896 \\
\hline 6. & Bleeding & 55 & 0 & 0 & 55 & 100 & 100 & $<0.001$ \\
\hline 7. & Tourniquet & 32 & 18 & 24 & 14 & 25.4 & 0.00 & 0.989 \\
\hline
\end{tabular}

\begin{tabular}{|c|c|c|c|c|c|c|c|}
\hline \multirow{3}{*}{$\begin{array}{l}\text { Tab } \\
\text { SN }\end{array}$} & e 4: Hematolo & ical Prof & of $\mathrm{C}$ & ses. & & & \\
\hline & \multirow[t]{2}{*}{ Finding } & \multirow[t]{2}{*}{$\begin{array}{l}\text { Total } \\
(\mathbf{n}=130)\end{array}$} & \multicolumn{2}{|c|}{$\begin{array}{l}\text { Group I } \\
(n=75)\end{array}$} & \multicolumn{2}{|c|}{$\begin{array}{l}\text { Group II } \\
(n=55)\end{array}$} & \multirow[t]{2}{*}{ 'p'value } \\
\hline & & & No. & $\%$ & No. & $\%$ & \\
\hline \multirow[t]{5}{*}{1} & Hb level & & & & & & \\
\hline & $<8 \mathrm{~g} / \mathrm{dL}$ & 7 & 6 & 8 & 1 & 1.81 & \multirow[b]{4}{*}{0.342} \\
\hline & $8-10 \mathrm{~g} / \mathrm{dL}$ & 15 & 9 & 12 & 6 & 10.9 & \\
\hline & $10-12 \mathrm{~g} / \mathrm{dL}$ & 39 & 28 & 37.3 & 11 & 20 & \\
\hline & $>12 \mathrm{~g} / \mathrm{dL}$ & 69 & 32 & 42.7 & 37 & 67.2 & \\
\hline \multirow[t]{4}{*}{2.} & TLC (/cumm) & & & & & & \\
\hline & $<4000$ & 31 & 17 & 22.7 & 14 & 25.5 & \multirow[b]{3}{*}{0.247} \\
\hline & $4000-11000$ & 72 & 45 & 60 & 27 & 49.1 & \\
\hline & $>11000$ & 27 & 12 & 16 & 15 & 27.3 & \\
\hline 3. & $\begin{array}{l}\text { Hematocrit } \\
>35 \%\end{array}$ & 65 & 41 & 72.7 & 24 & 68.9 & 0.728 \\
\hline \multirow[t]{6}{*}{4.} & $\begin{array}{l}\text { Platelet count } \\
(/ \text { cumm })\end{array}$ & & & & & & \\
\hline & $<20000$ & 24 & 13 & 17.3 & 11 & 20 & \multirow{5}{*}{0.123} \\
\hline & $20000-50000$ & 40 & 15 & 20 & 25 & 45.4 & \\
\hline & $50000-100000$ & 29 & 16 & 21.3 & 13 & 23.6 & \\
\hline & $\begin{array}{l}100000- \\
150000\end{array}$ & 17 & 12 & 16 & 5 & 9.1 & \\
\hline & $>150000$ & 20 & 10 & 13.3 & 3 & 5.4 & \\
\hline 5. & $\mathrm{PT}>14 \mathrm{~s}$ & 64 & 38 & 50.7 & 26 & 47.1 & 0.341 \\
\hline 6. & APTT $>28 s$ & 58 & 22 & 29.3 & 36 & 65.4 & 0.220 \\
\hline
\end{tabular}

Relatively less common clinical features were vomitting, diarrhea and retro-orbital pain. None of the patients with positive serology reported any bleeding/hemorrhagic manifestations including ecchymosis, melina, hematemesis, etc.

\section{Discussion}

Hematological parameters have been shown to provide some useful information regarding dengue severity and have been shown to correlate with the clinical spectrum and outcome.
Hence, it is essential that the relationship between hematological parameters and clinical spectrum of dengue fever is properly understood. Thus, the present study was taken up in order to describe the hematological profile in different clinical spectrums of dengue. Out of a total of 130 serologically proven cases of dengue fever, 55 cases (42\%) had bleeding manifestations during the course of study. The prevalence of bleeding manifestations among dengue patients has been shown to vary substantially in different studies.6in their study reported bleeding manifestations in $34.6 \%$ patients while. ${ }^{[7]}$ reported them in $32 \%$ of their series of dengue patients. ${ }^{[8]}$ in their series reported bleeding manifestation in only $9.58 \%$ of cases while. ${ }^{[9]}$ The frequency of dengue fever in the study was higher in the group aged 2130 years old followed by 31-40 years. These results are similar to those of a epidemiological study. ${ }^{[10]}$ This is most probably because of occupational exposure. There were very few children and no infant was affected in our series. This is contrary to most other reported studies from India. ${ }^{[11,12]}$ The most significant laboratory abnormality seen in our patients was thrombocytopenia, as observed in other studies. The mechanism for thrombocytopenia and platelet destruction is again multifactorial. There is reduced platelet production because of direct damage to the megakaryocytic precursors (CFU-Meg). Also, there is increased peripheral destruction by pre-existing antibodies leading to immune complex formation with viral antigen and fixation on platelet surface leading to innocent bystander immune destruction. Antiplatelet antibodies (APA) are also produced by NS1 antigen which cross reacts with integrins and adhesins leading to platelet aggregation.

In present study, we used both ELISA as well as Card methods to detect the dengue virus. For both the methods DENV non-structural 1 (NS1) protein antigen was most successful in diagnosis (66\%). Dengue NS1 antigen, a highly conserved glycoprotein, produced in both membraneassociated and secretion forms, is abundant in the serum of patients during the early stages of DENV infection. However, a number of cases in present study presented after a crucial delay. In such cases, IgGand IgM antibody diagnosis plays a crucial role. In present study we were able to diagnose $36 \%$ cases using $\operatorname{IgM} / \mathrm{IgG}$ antibody detection methods. In present study, fever (130\%), body ache (66\%), vomiting $(50 \%)$, bleeding (55\%), hepatomegaly $(44 \%)$, rashes $(38 \%)$ and tourniquet $(32 \%)$ were the most common presenting complaints. Among patients with bleeding manifestations, incidence of hepatomegaly was significantly higher as compared to that in patients without bleeding manifestations. Dominance of clinical features like bodyache, vomiting, rashes and bleeding has been shown in a number of other studies too, however, following fever, the most common presenting complaints variesin different studies. ${ }^{[6]}$ In present study, the difference in pattern of changes in thrombocytopenia could be owing to the fact that the present study was carried out at a tertiary care centre where most of the cases of DF were referred from primary and secondary care services and hence, the chronology of changes in laboratory parameters could vary slightly keeping in view the fact that we made assessments from the day of admission rather than from the day of onset of illness. However, the present study endorses the recovery trends in 
platelet count as reported by who reported platelet count of 55000 and $85000 /$ cumm respectively on day 1 and day 5, thus showing that on day 5 the recovery trend of platelets is initiated among patients undergoing treatment. ${ }^{[13]}$

\section{Conclusion}

In the current study the clinical profile of patients having bleeding manifestations which is the extreme form of dengue fever was marked by raised portion of hepatomegaly and decreased platelet count. The clinical course of disease is marked by a rationalization of platelet count by day 5 of illness. Dengue fever does not have specific medical therapy hence clinical recovery monitoring is largely dependent on haematological parameters. This study concludes that parameter like platelet count, haematocrit, leukocyte count and coagulation studies aid greatly in clinical monitoring of patient. The study results are relevant in the characterization of evolution of the disease as well as the haematological dynamics involved and can be used as screening tools by physicians to chart early therapeutic response. The present study was also limited by the duration of follow-up and outcome evaluation, including relapse. Hence, further studies with longer duration of follow-up and outcome evaluation, and focus on calculating the time delay between onset of fever and admission to our facility might provide some valuable clue that might help in understanding this relationship further.

\section{References}

How to cite this article: Kovil A. Evaluation of Patients with Dengue Infection for Their Clinical and Hematological Profile, Management and Outcomes at Mount Zion Medical College Hospital in Kerala. Acad. J Med. 2018;1(1):13-16.

DOI: dx.doi.org/10.21276/ajm.2018.1.1.5

Source of Support: Nil, Conflict of Interest: None declared.
1. Tripathi SM, Mishra N. Late Onset Mania in Dengue Fever. Immunology and Infectious Diseases 2(1): 1-3,2014.

2. Chaudhuri M. What can India do about dengue fever? BMJ 2013; 346: f643. doi:10.1136/bmj.f643.

3. Simmons CP, Farrar JJ, Chau NV, Wills B. Dengue. N Engl J Med 2012; 366:1423-32

4. World Health Organization. dengue guidelines for diagnosis, treatment, prevention and control. 2009.

5. Oishi K, Saito M, Mapua CA, Natividad FF. Dengue illness: clinical features and pathogenesis. J Infect Chemother. 2007;13(3):125-33.

6. Butt N, Abbassi A, Munir SM, Ahmad SM, Sheikh QH. Haematologicaland biochemical indicators for the early diagnosis of dengue viral infection. J Coll Physicians Surg Pak. 2008May;18(5):2825 .

7. Vanamali DR, L Venugopal, P Yeshwanth, DilipRampure. A Study OnClinical, Laboratory Profile And Outcome Of Dengue Fever. Journal of Evolution of Medical and Dental Sciences 2013; 2(5):9739-9743.

8. KauserMM, KalavathiGP, RadadiyaM, KarthikM, AfreenA, Dengue Fever in Tertiary Care Hospital in Central Karnataka, India. Global J. Med. Res.: B. 2014; 14(5):7-12.

9. Khan MY, VenkateshwarluC, SandeepN, Krishna AH. A Study of Clinical and Laboratory Profile of Dengue Fever in a Tertiary Care Hospital, Nizamabad, Telangana State, India. Int. J. Contemp. Med. Res. 2016; 3(8):2383-2387.

10. Ageep AK, Malik AA, Elkarsani MS. Clinical presentations and laboratory findings in suspected cases of dengue virus. Saudi Med J. 2006;27(11):1711-3.

11. Singh NP, Jhamb R, Agarwal SK, Gaiha M. The 2003 outbreak of dengue fever in Delhi, India. Southeast Asian J Trop Med Public Health. 2005;36(5):1174-8.

12. Gajera VV, Sahu S, Dhar R. Study of haematological profile of dengue Aug;3(3):A241-6.

13. JameelT, MehmoodK, MujtabaG, ChoudhryN, Afzal N, Paul RF. Changing haematological parameters in dengue viral infections. J AyubMed CollAbbottabad. 2012 Jan- Mar;24(1):3-6. KumaraswamyRC et al.. A Study of Clinical and Laboratory Profile of fever and its clinical implication. AnnalAppl Bio-Sci. 2016 